\title{
LA-UR-12-24177
}

Approved for public release; distribution is unlimited.

Title:

Author(s):

Intended for:

\section{Town of Taos Dispatch Center}

\author{
Brooks,Marla J \\ Ulibarri,Richard A
}

Outreach to Taos. Analysis and recommendations for their regional dispatch/EOC operation/relocation

Disclaimer:

Los Alamos National Laboratory, an affirmative action/equal opportunity employer,is operated by the Los Alamos National

Security, LLC for the National NuclearSecurity Administration of the U.S. Department of Energy under contract DE-AC52-06NA25396. By approving this article, the publisher recognizes that the U.S. Government retains nonexclusive, royalty-free license to publish or reproduce the published form of this contribution, or to allow others to do so, for U.S. Government purposes.

Los Alamos National Laboratory requests that the publisher identify this article as work performed under the auspices of the

U.S. Departmentof Energy. Los Alamos National Laboratory strongly supports academic freedom and a researcher's right to publish; as an institution, however, the Laboratory does not endorse the viewpoint of a publication or guarantee its technical correctness. 


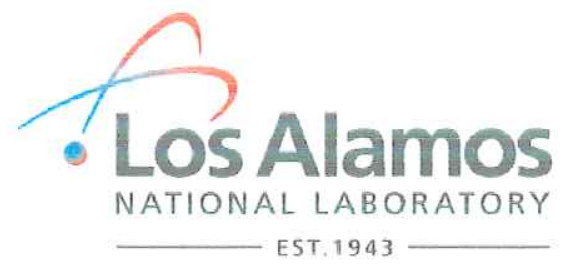

\title{
Los Alamos National Laboratory Town of Taos Dispatch Center
}

\author{
August 15, 2012
}

Marla Brooks, Emergency Management LANL

Rick Ulibarri, Government Affairs LANL 


\section{TABLE OF CONTENTS}

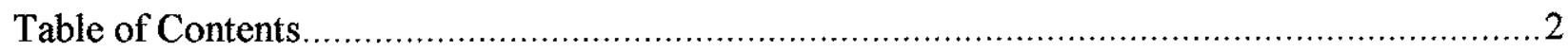

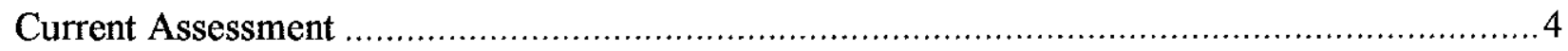

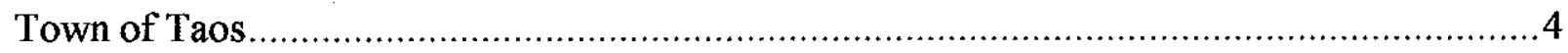

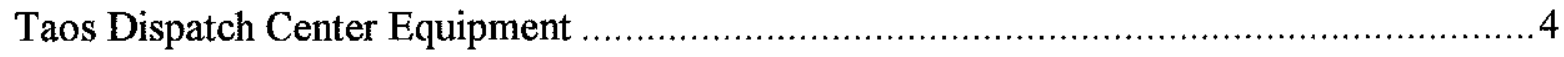

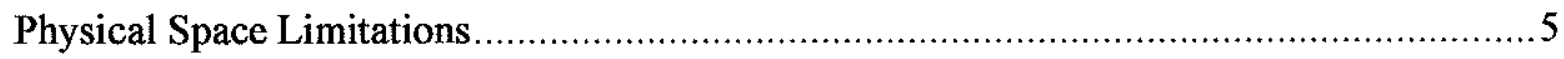

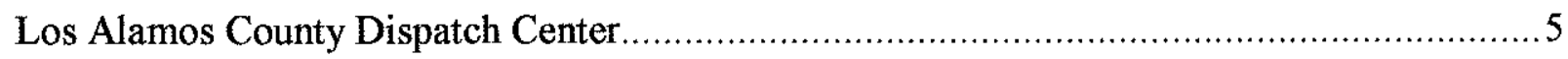

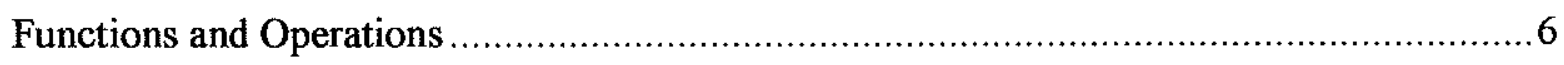

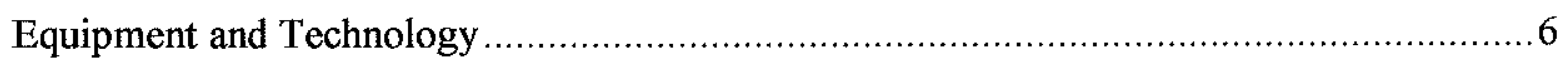

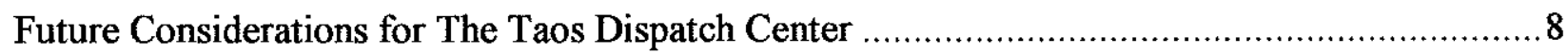

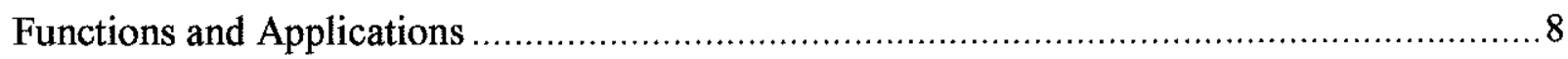

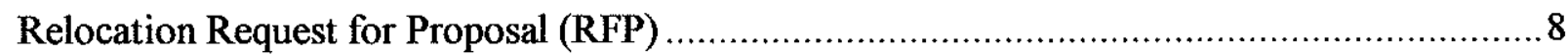

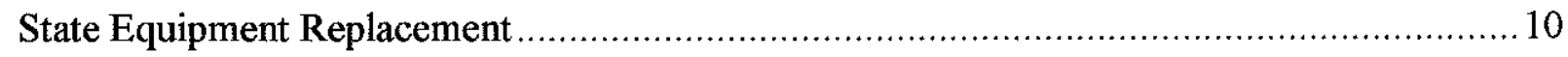

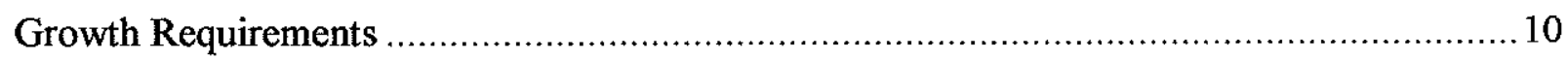

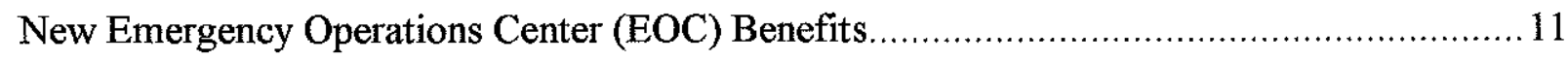

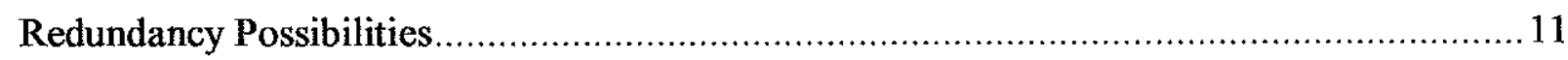

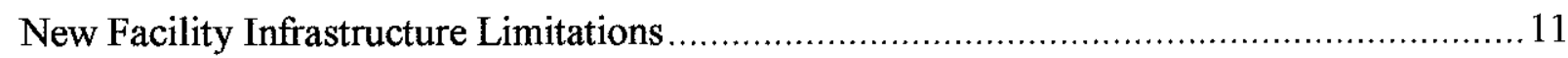

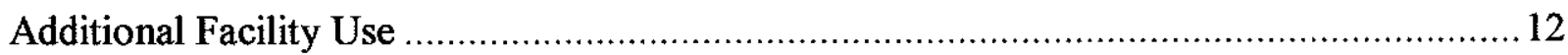

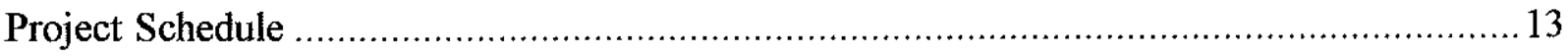

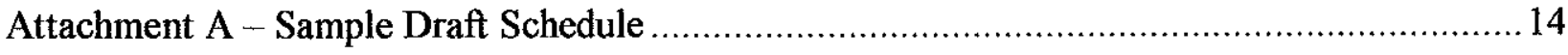




\section{ACRONYMS \& ABBREVIATIONS}

\begin{tabular}{|l|l|}
\hline Acronym/Abbreviation & Definition \\
\hline ANI/ALI & Caller's location/Caller's phone number \\
\hline CAD & Computer-Aided Dispatch \\
\hline DFA & Department of Finance Administration (Taos) \\
\hline EMD & Emergency Medical Dispatch \\
\hline EMS & Emergency Medical Services \\
\hline EOC & Emergency Operations Center \\
\hline GIS & geographic information system \\
\hline INFOR & I/Informer driver's license and vehicle registration check \\
\hline LANL & Los Alamos National Laboratory \\
\hline MSAG & Master Street Addressing Guide \\
\hline NCIC & National Crime Information Center \\
\hline PSAP & Public Safety Answering Point \\
\hline ProQA & Medical Priority Dispatch System software \\
\hline RFP & Request for Proposal \\
\hline SOW & Statement of Work \\
\hline RMS & records management system \\
\hline UPS & universal power supply \\
\hline VPN & virtual private network \\
\hline & \\
\hline
\end{tabular}




\section{CURRENT ASSESSMENT}

\section{Town of Taos}

The current Taos Regional Dispatch Center (hereafter referred to as the Center) is located in the Taos Police Department Complex. The Center has appropriate security measures to protect the operation, information, and employees. Locking doors and a palm reader restrict access to this area. This Center provides personnel who provide the following services:

- Fire and law enforcement dispatch services to the Town of Taos Police, Sheriff's Officers, Questa, and the Taos Ski Valley,

- Medical dispatch calls for the area,

- Monitoring of the jail holding cell,

- Answering non-emergency traffic into the center.

Red River serves as the backup Dispatch Center for Taos. The current Center is staffed with two dispatchers, at all times, and staff is increased as necessary for increased activity and events. A Lead Dispatcher/Supervisor at the Center is knowledgeable about the operation and existing equipment of the Center.

\section{Taos Dispatch Center Equipment}

Currently, the Center has adequate equipment to handle the services described above that it provides to the regional area. Included in this equipment are the following:

- a server room with 6 racks,

- a Goserco radio recorder,

- mapping/geographic information system (GIS) software,

- five dispatch stations,

- National Crime Information Center (NCIC) access,

- Computer-Aided Dispatch (CAD) software,

- Valcon radio consoles,

- Plant Vesta 911 system,

- mapping capabilities - including cellular, 
- nine (9) phone lines serve the center ( 3 for 911 calls, 3 are wireless capable, and 3 administrative),

- one monitor for monitoring the holding cell for law enforcement,

- capability to get a quick record recall records management system (RMS).

Radio systems for the Center are new and adequate for the function of the Center. Mapping is five years old and has no tracking capability. The CAD was purchased around 1997 and will probably need to be replaced with a more interactive, integrated system in the near future. A CAD system should be able to integrate desired applications such as NCIC, mapping, and the 911 system.

The servers that service the Center are located in the Town Hall building. A natural gas generator is available when needed, and each group of servers is supported by a universal power supply (UPS).

The antennae servicing the Center has been redone and upgraded. It is unknown whether this antenna could be re-located to a new site or not. A feasibility study should be conducted to determine if this is a cost savings measure or even a viable solution.

\section{Physical Space Limitations}

The current dispatch function is located within the Taos Police Department complex. The bathroom located within the Center is convenient. This allows for necessary breaks without operators having to leave their immediate work area. Space afforded to the five dispatch stations is very limited, however. There is no room for growth, and the stations are in close proximity to each other. There is also limited area for storing items, such as supplies, references, replacement equipment, etc. In addition, there is inadequate space for employee storage or a break room for these dispatchers. The servers/computer room is adequate and appears to fulfill the current needs of the Center. No separate space is dedicated to a supervisory station. Overall, the Center is adequate, but there is limited room for the growth and evolving functionality needs of the Center. In the next few years, the next generation of 911 technology will require higher bandwidth and more robust processing capabilities. More staff may be needed at that time to handle the increased functional and technical demands.

\section{Los Alamos County Dispatch Center}

Los Alamos County has a state of the art Dispatch Center that dispatches police, fire, and Emergency Medical Services (EMS) for the County of Los Alamos, which includes the Los Alamos National Laboratory (LANL). The Los Alamos Dispatch Center is staffed with a minimum of two (2) dispatchers at all times. Both dispatchers are dedicated to 911 calls and to the ProQA - medical dispatch. 


\section{Functions and Operations}

Dispatch staff is comprised of fourteen (14) individuals, including one management position. Training, Master Street Addressing Guide (MSAG), and Terminal Agency Coordinator (TAC) duties are assigned to one of the remaining positions. There are twelve (12) positions assigned to the floor, which are divided into three shifts.

The basic dispatch functions include the following:

- answering 911 calls;

- dispatching medical calls (at least one (1) Emergency Medical Dispatch (EMD) licensed dispatcher is on duty at all times);

- dispatching fire calls;

- dispatching law enforcement calls;

- answering all incoming lines, off hours utilities, and animal control calls; and

- monitoring walk in traffic.

The Dispatch Center is located at and managed by the Los Alamos Police Department. Security to the Center is tight and controlled. Access to the Center is limited and follows strict NCIC guidelines (finger print and background checks for those with access as outlined by NCIC requirements). The center is supported by a UPS and generator system; Santa Fe County is the backup Center for Los Alamos should a need arise.

\section{Equipment and Technology}

The Center has six (6) dispatch stations. Phone lines include four (4) 911 lines, three (3) wireless 911 lines, and an administrative rollover line. The following equipment is operational in the Center:

- NCIC (Note: Los Alamos uses a virtual private network (VPN) for their NCIC instead of having a hard-wired terminal).

- 911 Plant Vesta - this is tied into the GPS mapping system, which integrates with their Computer-Aided Dispatch (CAD) system.

- Computer Aided Dispatch (CAD). The Los Alamos Center CAD is an Intergraph system, which is a robust operating system that integrates multiple functions/applications into one so that all can be viewed and integrated onto one screen. Additionally, this system is populated with all necessary fire and EMS information for ease in dispatching fire and medical calls. 
- Records Management System (RMS). This system consists of electronic software for tracking all calls, reports, etc. Dispatchers provide input to the CAD system, which interfaces with the RMS and continually updates and provides information into the RMS system.

- I/Informer (INFOR), a driver's license and vehicle registration information check, which is integrated through the CAD software. Note: the State of New Mexico offers this for free depending on the CAD vendor.

- Mobile Data NCIC for police officers on their potable laptops.

- Training station, used for training on the dispatch equipments and ProQA medical dispatch proficiencies.

- Recording of all calls into and out of the Center, including radio traffic.

Each dispatch station is equipped with separate, dedicated PCs for the CAD application, another for the Plant Vesta application, and an additional one for the radio, while also having multiple monitors that support each function.

Most of the storage for the Center is electronic, resulting in minimal additional space requirements. There are a number of storage mandates, however, including:

- NCIC - must be kept for a minimum of one (1) year;

- protection orders;

- warrants;

- entries into NCIC;

- Department of Public Safety NCIC audits; and

- MSAG paperwork, training records, and time sheets.

The Center has several large file cabinets that are adequate for storing these documents. The Center also has lockers for each dispatcher, mailboxes, and a supply area.

There is a fax machine, copy machine, scanner, printers, an NCIC printer, a 911 printer (which can be provided by the state), and a shredder. Four (4) server racks support the dispatch operations, with an additional two racks for the Plant Vesta equipment. A recording system is located with the servers and records all dispatch traffic.

Phone service is provided by Century Link, and Motorola supports the radios. 


\section{FUTURE CONSIDERATIONS FOR THE TAOS DISPATCH CENTER}

\section{Functions and Applications}

The Los Alamos model for dispatch functions, and their supporting applications, integrates many of the necessary functions through one operating system. The CAD is the main hub where GIS, RMS, INFOR, ProQA, and 911/GIS are integrated together, thus allowing for greater ease in dispatch functions and a more efficient operation. The CAD system that Los Alamos uses is not unique to this capability.

Please note that careful planning for replacement of the CAD is critical. Future application integration can be realized with a thorough understanding of CAD system features and capabilities. An example is the free $\mathrm{I} / \mathrm{Informer}$ that the state will provide, depending on the CAD vendor.

Consideration should also be given to future wireless capabilities for the Center. An example is the use of a VPN for the NCIC. This would free up the burden of having a hard-wired terminal.

The RMS that the County/Police Department Records Department uses is one that can integrate with whatever CAD system that the Center uses. This needs to be a consideration when changing software/system applications for both dispatch and records.

If not already present, consider the integration of GPS mapping into the CAD system, and make sure that it is tied to the 911 Plant Vesta function.

There is an increased probability of stricter regulations regarding medical dispatch in the future. Evaluation of the current system for medical dispatch should take place, and consideration should be given into the possibility of using ProQA or a similar process. The Medical Director for your medical dispatch should be able to identify the appropriate hardware/software applications and compliance issues that are needed to keep your licensing. An additional training station would also be of value to the Taos Dispatch Center. The training station could be used for all dispatch functions, including medical dispatch. Additionally, a quality performance tracking system could be used at this station to track the regulatory medical dispatch data.

Consideration should be given to the monitoring of the Police Department holding cell. If this function is to remain with the Center, then replacement of that system may be necessary. Moving this function to a new location, however, may be cost prohibitive. State-of-the-art monitoring equipment should be capable of recording both visual and audio signals unless otherwise written into procedure as to intent of use (safety vs. evidence for court).

\section{Relocation Request for Proposal (RFP)}

During the RFP stage, the Town of Taos should be prepared to differentiate the "Taos Responsibilities" and the "Vendor Responsibilities." Taos could use a service agreement that explains responsibilities to be undertaken by both parties. Additionally, Taos must specify to the 
Vendor that the Vendor or its subcontractor (if allowed by Taos) will complete designated responsibilities. Note that after your RFP is awarded, a service agreement should be prepared and include at least the following:

- Statement of work (SOW) - describes the deliverable to be furnished and tasks to be performed in order to implement the relocation of your Center.

- Project overview - relocation of five dispatch stations to a new facility. The relocation requires the movement of existing equipments to the new facility.

- Project administration - outline both parties' responsibilities. For example, the Vendor assigns a project manager with authority to make project decisions and act as single point of contact. Taos assigns a project manager as a single point of contact that is also given authority to sign approvals.

- Project kickoff - review key actions, roles of participants, review project scope and objectives, review resources and schedules, review team interactions - meetings, reports, milestones, etc.

- Contract design review - review SOW, cutover plans, project schedule.

- System installations (important portion of document ) - define installation locations, contract execution, detail deficiencies of site, perform necessary upgrades to site, etc., NOTE: This is an important part of the agreement in that you outline what Taos will do (at a minimum), such as provide access; supply adequate electrical service for all functions of the center; provide grounding, lighting, and HVAC as needed for communication with sites; provide floor space; provide roof and wall penetrations for antenna coax and cabling, conduits, wire supports, and any other infrastructure needed for operation. If the Town of Taos can't do these things, it will need to be contracted out. In addition to electrical, the phone company will need to make sure that the new building has adequate equipment, connections, etc. to handle the new Center,

- Generator/UPS - define and ensure availability in the dispatch area and server room.

- Workstation furniture - define who will move the furniture.

- E-911call processing system- define the vendor's responsibilities for this step (prewired, relocate, make busy/transfer 911 to backup Public Safety Answering Point (PSAP), relocate reinstall PBX, ensure caller's location (ANI)/phone number (ALI) connections, perform functional testing, cutover/transfer 911 back to the new Center, provide cabling, miscellaneous materials, hardware, perform final testing, and develop installation documentation). This list is not all-inclusive; there could be more involved. Taos should define its actions. For example, you will need to provide phone lines and data feed for 
telephone lines (911 and administrative lines), provide coordination, provide the necessary electric infrastructure, etc.

- System Acceptance (this is critical and should be formal) - a written validation that all equipment installations are complete and accepted by Taos. Signed by both the Vendor and by Taos.

- Training - if you expect any training from the Vendor, it should be noted. You will also need to include a transition period that you expect the Vendor to stay on site to address any issues that arise after you cut over to the new Center location.

- Documentation (any documentation you expect from vendor) - floor plans, equipment rack configurations, test checklists, equipment inventory, etc.

- Project Status Meetings - identify the frequency of status meetings and who needs to attend (e.g., bi-weekly, onsite, etc.).

- Change Control

- Final Validation of Completion

Additionally, Taos will need to include all the legal sections that your attorney includes in contracts, such as licenses, indemnity, applicable law, insurance, use of documents, etc.

\section{State Equipment Replacement}

According to information received from Taos, the Department of Finance Administration (DFA) was to meet with Taos in July 2012 and work on the approval for the package. If the grant writing and submittal takes about a month, with approval to follow by the Town Manager, then DFA should be notified in August/September about the installation of equipment in the new facility. According to Taos, the Vendor authorization will be done sometime in September. A six (6) month window was allowed for equipment readiness and installation. March of 2013 would be an anticipated installation date. Taos will need to firm up this timeline, modify its requirements as necessary, and then ensure that the Vendor is aware of this timeline.

\section{Growth Requirements}

The Town of Taos is looking to relocate its five dispatch stations to a new facility. If dispatch service increases due to population, activity, or regulations (such as medical dispatch requirements), the Town may develop a need for additional dispatch stations. At a minimum, Taos should identify the location on the floor where an additional station could be placed and ensure the telephone, data, and electrical infrastructure is installed and ready for use during the relocation. If requirements for medical dispatch increase, the identification of a dispatch station for training and medical dispatch record keeping would be beneficial. Both Los Alamos County and LANL have a minimum of six stations available for use by dispatch staff. 
A dispatch supervisor location (office) is necessary in order to conduct supervisory tasks, store personnel records, conduct evaluations, etc.

Much of the new technology is headed toward wireless capabilities and electronic storage. In order to keep up with this technology and improve/grow the current operation, infrastructure and equipment planning and preparation is necessary.

\section{New Emergency Operations Center (EOC) Benefits}

The new facility affords the Town of Taos the opportunity to stand up a regional EOC. There are multiple jurisdictions and agencies within the area of the Town of Taos that would benefit from a central location available for use during emergency situations. Collaboration and cooperation is necessary when dealing with a crisis/emergency, and the necessity to have a centralized work location is critical. Since utilities play an important part in many emergencies, having Kit Carson Electric co-located in the same facility has synergistic benefits. It is important to realize that an EOC does not have to have state-of-the-art equipment and technology to be functional. These features can be phased in when funding becomes available. An EOC could be functional by supplying basic needs for those that would gather to command and control the emergency situation. Tables, phone lines, data feeds (computers), reference materials, white boards, and the like would be adequate to stand up an EOC. There is adequate room in the new facility to accommodate this type of operation.

\section{Redundancy Possibilities}

There is a potential to utilize the current antennae as a repeater for increased radio coverage. It is unknown at this time if this antenna could be moved and utilized at the new site. If not, the repeater possibility should be considered. If that is not possible, perhaps there is other Town radio traffic (buses, public works, etc.) that could utilize this antenna.

If relocated, the current Dispatch Center area might be utilized to monitor the holding cell activity and storage of records for the department.

\section{New Facility Infrastructure Limitations}

Both the current and new site location need to be adequately outfitted with electrical, data feed, and phone capability. Currently this appears to be a minimum on the dispatch floor. Growth will be difficult if this infrastructure is not there. Dispatch is staffed on a 24/7 basis, which increases the need for additional electrical outlets. Examples include phone charges, coffee pots, small refrigerators, heaters, fans, etc. The abundance of electrical capability is a must in a Center. There is not an adequate number of electrical outlets in the new Center. Installation of new outlets needs to be well thought out to avoid tripping hazards from cords. Floor outlets are ideal, in addition to an increase in the number of wall outlets. 
The new Center has adequate physical security posturing with a fence and limited access. Additional access limitations need to be in place for the Dispatch Center itself. The installation and use of cameras for outside view and door access should be considered.

The furniture provided for the Dispatch Center in the new complex is not ergo compliant. The workstations would need to be equipped with ergo furniture and chairs. The current Center has ergo workstations, which could be re-located to the new site.

Noise will be a problem at the new Center, as the ceiling is high, ducts are exposed and noisy, and there is an opening at the top to the first floor. A lowered ceiling or the covering of the duct work would be necessary. Any NCIC information would be limited to hard copies only, and there would have to be assurance that the residents on the top floor could not hear or see any NCIC information. This is regulated by the FBI, and the Center must be compliant with these regulations. (Perhaps the center's FBI NCIC contact could offer some suggestions.)

The Center has access to bathrooms and a kitchen area. Both are outside of the dispatch floor area but in close proximity.

There is no radio antenna at this location, so there would have to be a scoping of the site for an antenna or a micro-wave type solution. Once that is scoped, you will need to determine how to physically protect that location. It is unknown as to whether the sighting would be within the current security posturing for this building.

A review of the technical needs both from the Taos Information Technology lead and a proposal from Motorola yielded a comprehensive list of materials and equipments that will be needed to make the new Center ready for the move. Many of the identified needs could be met by the Town staff in a cost effective manner. For example, the Town staff could directly purchase and install assorted items such as, but not limited to, Ethernet cabling, switches, routers, connections, and the like.

There is discrepancy on the age of the radio system. LANL understood the radios to be fairly new, but in the Motorola quote they were listed as old and in need of replacement. This is a critical point, as the radios are very important to all the other functions and system integration. If indeed the radios are older and need replacement, Motorola has provided a recommendation that would work in the new Center.

Overall, the new facility is a viable possibility for the relocation of the Dispatch Center. However, there is infrastructure work that will need to be done prior to the move. This work should be considered when scheduling the project.

\section{Additional Facility Use}

The space available for use by the Town of Taos is large and capable of housing more than just the Dispatch Center. The additional room could be set up to serve as an EOC for the region with 
very little effort. Phone lines, data feed, electrical availability, tables, chairs, white boards, and some filing cabinets could be set up for use during emergency situations. This operations center could grow with additional and upgraded technology as money is available. To have a center capable of gathering affected agencies/organizations is the primary need. Additionally, this new facility could serve as a sub-station for the police. An officer would not have to be dedicated to the Center but a desk, phone, chair, and computer could be located at the Center for use by officers as need arises. This addition would promote the continued interaction between officers and dispatchers. Generally, communities like the additional presence of officers in the community, as it further generates the idea of community policing.

\section{Project Schedule}

Based on the Town of Taos' desired end date, the development and review of a draft project schedule is necessary in developing a critical path for implementation. Taos will need to review said draft project schedule to determine if feasible and if the required deadline can be met (see attachment A - Sample Draft Schedule). 


\section{ATTACHMENT A - SAMPLE DRAFT SCHEDULE}

This schedule may give Taos an idea of the many tasks and timeline necessary to complete in order to meet your deadline. The schedule is broken down into weeks with key tasks identified for each block. Note that this is not a project plan, but rather an informal checklist to be followed in order to keep on track.

July, 2010

- Week of $7 / 19-23 / 10$

- Initial contact with parties involved

- 7/20/10-Met with IT reference needs/plan

- 7/21/10-Contacted Qwest reference needs/quotes

- Week of $7 / 26-30 / 10$

- 7/28/10-Meet with Radio Shop reference needs/quotes

- Follow up with Motorola

- Contract signed?

- Contract received?

- Draft letter to Motorola reference dates for move

- Follow up with Victor/Anne

- 7/22/10 Capt. would talk with them about infrastructure.

- Part of project, designated dispatch space

\section{August, 2010}

- Week of $8 / 2-6 / 10$

- Arrange with Motorola for date of move if not already set

- FOLLOW UP WITH CONTRACT FROM VP

- Has Contract been received?

- Contact Facilities for coordination of move

- Schedule notification requirements on timeline

- Meet with all parties involved-Meeting set $8 / 3 / 10$

- Who will do DMark?

- Drop circuits

-

- Contact Qwest Manager

- Follow up with LANL Radio Shop

- Names of Qwest Federal contacts

- Checking into $T 1$ redundancy

- Week of 8/9-13/10

- Begin design of space-IT needs before wires

- Motorola date received?

○ IT 
- Contact Radio Shop 612 pair confirmed (see notes $8 / 3 / 10$ )

- Dale check pipes in Dispatch-where do they go? (see notes $8 / 3 / 10$ )

- Server room

- Fire suppression

- Strobes

- Battery start up

- Contact Facilities

- What need for physical move? (See notes $8 / 3 / 10$ )

- Specs on furniture

- Date for Backer Board (See notes 8/3/10)

- Ground bar in place in server room? (see notes $8 / 3 / 10$ )

- Pipe to server (see notes $8 / 3 / 10$ )

- 200 pair (see notes $8 / 3 / 10$ )

- Week of 8/16-20/10

- Contact Motorola

- Conference call 8/19

- Follow up with Radio Shop

- E-mailed IT about running over existing channel bank? See notes $7 / 28 / 10$

- Simplex capabilities PD

- New screens for Radios?

- modems, black box all fine, do not need replacement

- New PCs? Currently work fine, are 4-5 years old

- Contact IT

- Contact Facilities

- Week of 8/23-27/10

- Meet with Motorola/Advanced 8/24/10

- Contact Facilities

- Furniture specs

-

- Contact IT

- Server room needs met?

- Week of $8 / 30-9 / 3 / 10$

o vacation 


\section{September, 2010}

- Week of 9/6-10/10

- Advance

- UPS need

- written confirmation of 4 UPS v. larger unit

- Quote for pulling additional wires

- Received?

- Received 9/8/10

- Contact Qwest

- confirmed need 30-45 days lead time notification

- Contact Facilities

- Design of space

- Completion of electrician (see notes 8/24/10 CIP to pay for electrician and work, notes conversation with Victor $9 / 7 / 10$ )

- Date to have outlets changed to $30 / 120$

- Ground Bar in Dispatch space?

- Contact IT

- Received info from Dieter?

- Contact with Advance?

- check UPS lead time

- Server room needs met?

- Contact Qwest for 30-45 day confirmation

- E-mail received 9/8/10 confirming 30-45 days advance notice.

- Contact Radio Shop

- Channel Bank decision

- Simplex capabilities

- Week of 9/13-17/10

- Qwest notification of move date

- 45 days in advance of move

- Advanced contact

- Updated Quote

- Received?

- Signed?

- Date for wires pulled?

- Okay for individual UPS or need large one? (see binder $9 / 7 / 10$ )

- Contact Facilities

- Design of space

- Outlets changed?

- Ground bar for Dispatch?

- What needed for physical move?

- Contact Radio Shop 
- Channel box?-Check on Chief's info

- Archive system?

- Downtime for radio when moved?

- Simplex?

$\circ$ IT

- Decision about Xerox being on UPS or going down and then back up

- Lead time on UPS? See notes 9/7/10

- Information on UPS from Advance (see binder 9/7/10, notes 9/9/10)

- IT Server room?

- e-mail Advanced information

- Shift Supervisors and staffing needs addressed

- E-mailed Shift Supervisors 9/19/09

- Week of $9 / 20-24 / 10$

- Motorola

- CONTRACT??

- Advanced

- Quote received?

- Downtime from Motorola for SFRECC?

- SFRECC notified

- Electric

- Facilities

- Final design of space

- CDC Sup office?

- Becks

- Meet with 9/21/10

- Radio

- Channel bank paid for?

- IT needs

- UPS ordered?

- Final power count includes simplex base stations?

- Channel bank follow up-Charles Industries model break out

- T-1 lines ordered?

- See e-mail

- Week of $9 / 27-10 / 1 / 10$

- Electric

- See e-mail

- Facilities

- E-mail list of items to be moved and schedule of moves

- handling purges at $C D C$

- Becks

- Quote received? 
$\circ$ IT

- Advanced

- Quote

- Signed?

- Motorola PO received?

- Schedule?

- Qwest

- Confirmation of lines moved

\section{October, 2010}

- Week of $10 / 4-8 / 10$

- Electric

- See e-mail

- Facilities

- Initial items move scheduled

- IT

- Week of 10/11-15/10

- Contact SFRECC

- Facilities

- IT

- Advanced/Motorola

- Week of 10/18-22/10

- IT finalization

- Radio Shop finalization

- Qwest finalization

- Staff finalization

O Facilities

- Move of two stations and all other possible items

- Week of 10/25-29/10

- Advanced/Motorola

- Radio Shop

- Radios in place?

○ IT

m County network established/verified

- MOVE! 